\title{
AVALIAÇÃO DE CULTIVARES DE MANDIOCA NA REGIÃO NOROESTE DO PARANÁ( ${ }^{(1)}$
}

\author{
PEDRO SOARES VIDIGAL FILHO ${ }^{(2)}$; MANOEL GENILDO PEQUENO ${ }^{(4)}$; \\ CARLOS ALBERTO SCAPIM ${ }^{(2)}$; MARIA CELESTE GONÇALVES VIDIGAL ${ }^{(2)}$; \\ ROGÉRIO RUI MAIA ${ }^{(3)}$; EDVALDO SAGRILO ${ }^{(3)}$; \\ GUSTAVO ANDRÉ SIMON(3); RIVAEL SINIZ LIMA ${ }^{(3)}$

\section{RESUMO}

As cultivares de mandioca IAC 12, IAC 13, IAC 14, Fécula Branca, Espeto, Branca-de-Santa Catarina, Fibra, Verdinha e Mico foram avaliadas quanto à produção de raízes, parte aérea, teores de matéria seca e resistência à bacteriose, nos anos agrícolas 1994/95, 1995/96 e 1996/97, na localidade de Araruna, noroeste do Paraná. Utilizou-se o delineamento em blocos completos casualizados, com quatro repetições. Na análise conjunta verificou-se efeito significativo $(\mathrm{P}<0,05)$ da interação cultivares vs. anos para todas as características avaliadas. Apesar da interação foi possível concluir, de modo geral, que as maiores produções de parte aérea foram obtidas na cultivar IAC 14. Em relação à produção de raízes tuberosas as cultivares Fécula Branca, Mico, Fibra, Espeto, IAC 14 e Verdinha mostraram-se mais produtivas na média dos três anos. As cultivares IAC 14, Fécula Branca, IAC 13 e IAC 12 apresentaram os maiores teores de matéria seca nas raízes tuberosas. Quanto à bacteriose as cultivares Mico, IAC 14 e Fécula Branca mostraram-se mais resistentes.

Palavas-chave: Manihot esculenta, cultivares, produtividade, matéria seca, resistência bacteriana.

\section{ABSTRACT \\ EVALUATION OF CASSAVA CULTIVARS IN NORTHWEST REGION OF PARANÁ STATE, BRAZIL}

Nine cassava cultivars IAC 12, IAC 13, IAC 14, Fécula Branca, Espeto, Branca-de-Santa Catarina, Fibra, Verdinha and Mico were evaluated for roots and branches productivity, dry matter contents and bacterium resistance. The trials were carried out during the years of 1994/95, 1995/96 and 1996/97, in Araruna, Northwest Region of Paraná State, Brazil. The treatments were arranged in a randomized complete block design with four replicates. In the joint analyses, the cultivar vs. year interaction effect was significant $(\mathrm{P}<0,05)$ for all the characteristics evaluated. In spite of that, it was possible to conclude that IAC 14 and Fécula Branca had the highest branch yield and root yield, respectively. The cultivars IAC 14, Fécula Branca, IAC 13 and IAC 12 presented the highest root dry matter contents. Mico, IAC 14 and Fécula Branca showed the highest bacterium resistance.

Key words: Manihot esculenta, cultivars, productivity, dry matter, bacterium resistance.

\section{INTRODUÇÃO}

O Estado do Paraná é um dos maiores produtores de mandioca do Brasil, com área equivalente a 145.000 ha e produtividade média de raízes de
20,7 tha ${ }^{-1}$ (GRохко, 1997). Nos municípios onde predomina a maior concentração de área da cultura, o produto pode ser utilizado em forma de farinha e fécula para o consumo humano e como ração animal (DORETTO, 1993).

$\left({ }^{1}\right)$ Recebido para publicação em 6 de novembro de 1998 e aceito em 14 de março de 2000.

$\left({ }^{2}\right)$ Departamento de Agronomia (DAG) / Universidade Estadual de Maringá (UEM), 87020-900 Maringá (PR). E-mail: psvfilho@uem.br.

(3) Acadêmico de Agronomia. DAG/UEM, Maringá.

$\left({ }^{4}\right)$ Emater-PR, Escritório Regional, 87300-030 Campo Mourão (PR). 
A produtividade média da cultura da mandioca no Estado do Paraná, ainda que considerada elevada, poderia ser aumentada através do controle das condições de solo, clima e ação de agentes patogênicos, bem como do aprimoramento das práticas culturais (MATOs et al., 1981).

Embora seja uma planta rústica a mandioca sofre pressão de agentes patogênicos, especialmente a bacteriose causada pela Xanthomonas campestris pv. manihotis, cujos danos podem reduzir a produtividade em até 50\%, dependendo das condições climáticas, do potencial genético das cultivares e da qualidade do material de plantio (FUKUDA et al., 1984). Um dos maiores problemas da cultura da mandioca no Estado do Paraná é a carência de cultivares produtivas e resistentes a doenças. Os levantamentos recentes mostram que ao noroeste desse Estado predomina o cultivo de apenas duas cultivares (Fibra e Espeto), as quais, embora produtivas, apresentam baixo nível de resistência à bacteriose. Tal fato, aliado ao manejo inadequado da cultura, tem propiciado redução da produtividade, especialmente na região de Araruna, tradicional produtora de farinha de mandioca. Assim, torna-se necessária a diversificação de cultivares utilizando-se material genético com elevada capacidade produtiva e um manejo adequado da cultura, a fim de evitar a uniformidade genética e reduzir a possibilidade de epidemia da doença, que poderá comprometer a estabilidade do setor produtivo. Entretanto, trabalhos de pesquisa com cultivares de mandioca no Paraná são bastante escassos. SouZA e FASIABEN (1986) obtiveram maiores produções de raízes tuberosas no município de Rio Azul com as cultivares Palma-deUmuarama, Branca-de-Santa Catarina, IAC 12, Amarela-da-Fruticultura, Palma e Mico. Vidigal Filho $(1988)^{(5)}$, por sua vez, ao avaliar o comportamento de 38 cultivares de mandioca na região de Maringá, obteve maior produção de raízes tuberosas em um ciclo vegetativo com as cultivares Fibra, Casca Roxa, Mico, Vassourinha Maria, Dedo-de-Moça, Olho-Junto, Rolândia, Vassourinha Casca Escura, Castiana e SRT 1099-Taquari.

Em avaliação de germoplasma de mandioca coletado no município de Londrina (PR), AвBUD (1986) identificou uma cultivar de mandioca-de-mesa, denominada IAPAR 19-Pioneira, a qual, por apresentar ótimas qualidades culinárias, foi multiplicada e distribuída aos agricultores.

${ }^{5}$ VIDIGAL FILHO, P.S. Avaliação de cultivares de mandioca (Manihot esculenta Crantz), em Maringá, Noroeste do Estado do Paraná. Maringá, UEM/DAG, 1988. 53p. (Relatório de Pesquisa)
A introdução seguida de avaliações criteriosas, além de constituir o método de melhoramento mais simples e menos oneroso para seleção, em mandioca, apresenta grande probabilidade de êxito em função da ampla diversidade genética disponível ainda pouco explorada (FUKUDA, 1999). Nesse contexto surge a necessidade de substituição de cultivares tradicionais por outras, provenientes de trabalhos de seleção de germoplasma disponível ou através de recombinações, e adaptadas às condições edafoclimáticas de cada região (FUKUDA, 1993, 1999).

O presente trabalho teve por objetivo estudar o comportamento de cultivares de mandioca procedentes do Estado do Paraná e do Instituto Agronômico de Campinas, visando atender às necessidades da agroindústria da mandioca da região noroeste do Estado do Paraná.

\section{MATERIAL E MÉTODOS}

Foram conduzidos três experimentos na localidade de Araruna, noroeste do Paraná, nos anos agrícolas de 1994/95, 1995/96 e 1996/97, em área de ocorrência de Latossolo Roxo distrófico. A característica climática de Araruna é do tipo Cfb (conforme Köppen), com temperatura média anual de $21,5^{\circ} \mathrm{C}$ e precipitação média anual de $1.617 \mathrm{~mm}$.

Utilizaram-se, no presente trabalho, as cultivares de mandioca IAC 12, IAC 13, IAC 14, Fécula Branca, Espeto, Branca-de-Santa Catarina, Fibra, Verdinha e Mico, procedentes do Estado do Paraná e do Campo Experimental de Mandioca de Santa Maria da Serra do Instituto Agronômico de Campinas, cujas descrições botânico-agronômicas encontram-se nos quadros 1 e 2.

As manivas, com tamanho médio entre $15 \mathrm{~cm}$ e $20 \mathrm{~cm}$ foram plantadas horizontalmente, em sulcos, a aproximadamente $10 \mathrm{~cm}$ de profundidade. As parcelas foram constituídas por cinco linhas de oito plantas dispostas no espaçamento de $1,0 \mathrm{~m} \times 0,8 \mathrm{~m}$, com área útil de $14,4 \mathrm{~m}^{2}$ referente a dezoito plantas das três linhas centrais, desprezadas as bordaduras. O delineamento experimental utilizado foi o de blocos completos casualizados, com quatro repetições. Nos três anos de avaliação o plantio dos experimentos foi efetuado no período compreendido entre a primeira quinzena de agosto e a primeira quinzena de setembro, aplicando-se aos mesmos os tratos culturais recomendados por Normanha e Pereira (1950). Aos dez meses após a emergência procedeu-se à colheita das plantas.

Foram avaliadas as seguintes características:

a) altura média das plantas (ALTPLAN): expressa em $\mathrm{m}$, obtida pela medição a partir do nível do solo 


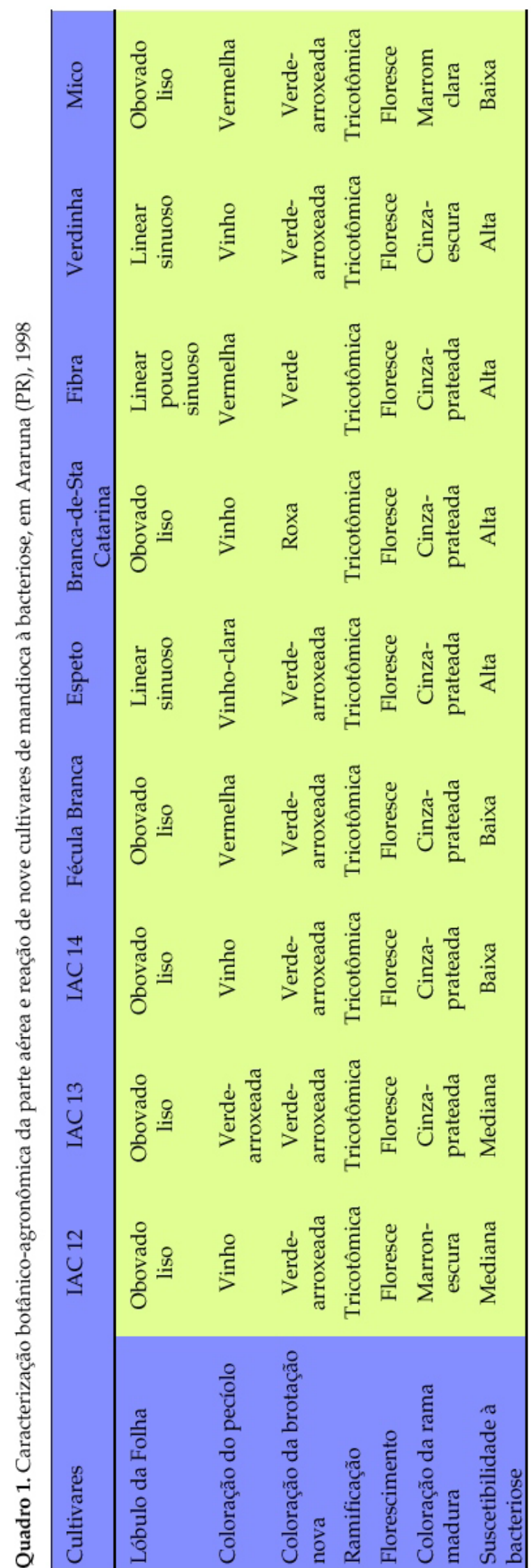

até o broto terminal de todas as plantas da área útil da parcela, por ocasião da colheita;

b) altura média da primeira ramificação (ALTRAMI): expressa em m, obtida pela medição do nível do solo até o ponto da primeira ramificação de todas as plantas da área útil da parcela, por ocasião da colheita;

c) produção média da parte aérea (PRODPAER): expressa em kg.ha ${ }^{-1}$, obtida pela pesagem da parte aérea de todas as plantas da área útil da parcela experimental;

d) produção média de raízes (PRODRAIZ): expressa em t.ha ${ }^{-1}$, obtida pela pesagem das raízes de todas as plantas da área útil da parcela experimental;

e) teor de matéria seca (MS): expresso em g. ${ }^{-1}$, obtido a partir de uma amostra de $5 \mathrm{~kg}$ de raízes tuberosas coletada em cada parcela experimental, conforme método descrito por GROSSMANN e FreITAS (1950);

f) índice de colheita (IC): expresso em \%, obtido por meio da relação entre o peso das raízes tuberosas e o peso total das plantas (raízes + parte aérea), segundo CONCEIÇão (1979);

g) incidência de bacteriose: avaliada aos 3 meses, 6 meses e 9 meses, em nível de campo, utilizando-se a escala proposta por FUKUDA et al. (1984).

A caracterização botânico-agronômica foi descrita conforme método de SiLVA (1981).

Os dados foram submetidos à análise de variância simples para cada experimento e, posteriormente, realizou-se a análise conjunta de acordo com as recomendações de BANZATTO e KRONKA (1995). Para a comparação das médias empregou-se o teste de Tukey a $5 \%$. A variável incidência de bacteriose foi analisada por meio da estatística descritiva.

\section{RESULTADOS E DISCUSSÃO}

A caracterização botânico-agronômica da parte aérea e das raízes tuberosas das cultivares de mandioca avaliadas, bem como sua reação à bacteriose, encontram-se nos quadros 1 e 2 . As cultivares Mico, IAC 14 e Fécula Branca apresentaram maior resistência à bacteriose, ao passo que as cultivares IAC 13 e IAC 12 apresentaram média resistência e as cultivares Branca-de-Santa Catarina, Verdinha, Fibra e Espeto apresentaram alta suscetibilidade.

O comportamento varietal em relação à bacteriose é relevante, pois, para se obter uma boa produtividade é necessário associar resistência à bacteriose, alto potencial produtivo e boa capacidade de adaptação (FUKUDA et al., 1983). Cabe ressaltar que a cultivar Fibra, embora tenha apresentado elevada suscetibilidade à bacteriose, ainda é uma das principais 
Quadro 2. Caracterização botânico-agronômica das raízes tuberosas de nove cultivares de mandioca em Araruna (PR), 1998

\begin{tabular}{|c|c|c|c|c|c|c|c|c|c|}
\hline Cultivares & IAC 12 & IAC 13 & IAC 14 & $\begin{array}{l}\text { Fécula } \\
\text { Branca }\end{array}$ & Espeto & $\begin{array}{l}\text { Branca-de- } \\
\text { Sta Catarina }\end{array}$ & Fibra & Verdinha & Mico \\
\hline $\begin{array}{l}\text { Espessura da } \\
\text { película suberosa }\end{array}$ & $\begin{array}{r}\text { Grossa, } \\
\text { rugosa }\end{array}$ & $\begin{array}{c}\text { Fina, } \\
\text { lisa }\end{array}$ & $\begin{array}{r}\text { Grossa, } \\
\text { rugosa }\end{array}$ & $\begin{array}{c}\text { Fina, } \\
\text { lisa }\end{array}$ & $\begin{array}{c}\text { Fina, } \\
\text { lisa }\end{array}$ & $\begin{array}{c}\text { Fina, } \\
\text { lisa }\end{array}$ & $\begin{array}{c}\text { Fina, } \\
\text { lisa }\end{array}$ & $\begin{array}{c}\text { Fina, } \\
\text { lisa }\end{array}$ & $\begin{array}{l}\text { Grossa, } \\
\text { rugosa }\end{array}$ \\
\hline $\begin{array}{l}\text { Coloração da } \\
\text { película suberosa }\end{array}$ & $\begin{array}{l}\text { Marrom- } \\
\text { escura }\end{array}$ & $\begin{array}{l}\text { Marrom- } \\
\text { clara }\end{array}$ & $\begin{array}{l}\text { Marrom- } \\
\text { escura }\end{array}$ & Clara & Creme & Creme & Creme & & $\begin{array}{l}\text { Marrom- } \\
\text { escura }\end{array}$ \\
\hline $\begin{array}{l}\text { Coloração da } \\
\text { camada cortical }\end{array}$ & $\begin{array}{l}\text { Creme- } \\
\text { clara }\end{array}$ & $\begin{array}{l}\text { Creme- } \\
\text { clara }\end{array}$ & Creme & Creme & & & & & Creme \\
\hline Coloração da polpa & Branca & Branca & Branca & Diantica & & & & & Branca \\
\hline Pedúnculo & Médio & Médio & Curto & Curto & Médio & Médio & Curto & Curto & Curto \\
\hline Cintas & Ausentes & Ausentes & Ausentes & Ausentes & Ausentes & Ausentes & Ausentes & Ausentes & Ausentes \\
\hline
\end{tabular}

cultivares exploradas pelos mandiocultores do noroeste do Estado do Paraná, cuja produção se destina ao fabrico de farinha. Esta cultivar introduzida no noroeste paranaense no início dos anos oitenta, além de produtiva era considerada resistente à bacteriose (LORENZI e DiAs, 1993).

Os resultados da análise de variância conjunta revelaram diferenças significativas $(\mathrm{P}<0,05)$ para os efeitos principais e para a interação cultivares vs. anos (Quadro 3). Nesse contexto a apresentação e discussão dos resultados serão efetuadas em função das médias das cultivares, em cada ano agrícola.

As médias referentes à altura de plantas, altura da primeira ramificação e produção de parte aérea obtidas nos anos agrícolas de 1994/95, 1995/96 e 1996/97, encontram-se no quadro 4.

No que concerne à viariável altura de plantas, a cultivar IAC 14 apresentou as maiores médias nos três anos agrícolas, diferindo significativamente das demais. As menores médias foram constatadas nas cultivares Fibra, Verdinha e Espeto. A variação dos valo- res observados para esse caráter sugere a influência, tanto de fatores de ambiente como de componentes genotípicos, expressa nas cultivares.

Para a variável altura da primeira ramificação (Quadro 4), observou-se que no ano agrícola 1994/95 as médias variaram de $0,64 \mathrm{~m}$ a $1,39 \mathrm{~m}$, com as cultivares IAC 14, Fécula Branca, Branca-de-Santa Catarina e Fibra apresentando as maiores médias, diferindo estatisticamente das demais. Por outro lado, no ano 1995/96 as cultivares Fibra e Fécula Branca sobressaíram-se, sendo, respectivamente, $215,1 \%$ e $188,6 \%$ superiores à cultivar Mico, a qual apresentou a menor altura de primeira ramificação. No ano agrícola 1996/97 as cultivares citadas anteriormente destacaram-se diferindo das cultivares Espeto, IAC 13, IAC 12 e Mico, que apresentaram os menores valores. Tal característica é importante no que diz respeito aos tratos culturais e à colheita, sendo, portanto, as cultivares preferidas pelos produtores, aquelas cuja arquitetura expressa-se em maior altura da primeira ramificação e, conseqüentemente, permitem maior

Quadro 3. Resumo da análise de variância conjunta das seguintes características: altura de plantas (ALTPLAN), altura da primeira ramificação (ALTRAMI), produção de parte aérea (PRODPAER), produção de raízes tuberosas (PRODRAIZ), matéria seca (MS) e índice de colheita (IC), obtidas no ensaio regional de cultivares de mandioca em Araruna (PR), durante os anos agrícolas de 1994/95, 1995/96 e 1996/97

\begin{tabular}{|c|c|c|c|c|c|c|c|}
\hline \multirow{2}{*}{ F.V. } & \multirow{2}{*}{ G.L. } & \multicolumn{6}{|c|}{ Quadrados médios } \\
\hline & & ALTPLAN & ALTRAMI & PRODPAER & PRODRAIZ & MS & IC \\
\hline Bloco/Ano & 9 & 0,09381 & 0,023926 & 25989460 & 18609340 & 36,99246 & 0,3128 \\
\hline Cultivar & 8 & $1,72011^{*}$ & $0,63288^{*}$ & $396511900^{*}$ & $193705200^{*}$ & $217,3688^{*}$ & $14,994^{*}$ \\
\hline Ano & 2 & $5,318961^{*}$ & $0,54617^{*}$ & $937303200^{*}$ & $149793300^{*}$ & $617,6654^{*}$ & $16,6459^{*}$ \\
\hline Cultivar vs. ano & 16 & $0,04856^{*}$ & $0,14735^{*}$ & $28093540^{*}$ & $68292820^{*}$ & $42,77194^{*}$ & $0,59457^{*}$ \\
\hline Resíduo & 72 & 0,013621 & 0,02029 & 8251431 & 8774857 & 11,63545 & 0,11395 \\
\hline C.V. (\%) & & 6,38 & 16,20 & 18,21 & 13,81 & 3,09 & 5,07 \\
\hline Média geral & & 1,83 & 0,88 & 15.774 & 21.443 & 348,6 & 59 \\
\hline
\end{tabular}

* Significativo ao nível de 5\% pelo teste F. 
Quadro 4. Médias e análise de variância das seguintes características: altura de plantas (ALTPLAN), altura da primeira ramificação (ALTRAMI) e produção de parte aérea (PRODPAER), obtidas no ensaio regional de cultivares de mandioca em Araruna (PR), durante os anos agrícolas de 1994/95, 1995/96 e 1996/97

\begin{tabular}{|c|c|c|c|c|c|c|c|c|c|}
\hline \multirow{3}{*}{ Cultivares } & \multicolumn{9}{|c|}{ Características } \\
\hline & \multicolumn{3}{|c|}{ ALTPLAN } & \multicolumn{3}{|c|}{ ALTRAMI } & \multicolumn{3}{|c|}{ PRODPAER } \\
\hline & $1994 / 95$ & $1995 / 96$ & $1996 / 97$ & $1994 / 95$ & $1995 / 96$ & $1996 / 97$ & 1994/95 & $1995 / 96$ & $1996 / 97$ \\
\hline & & & & & & & 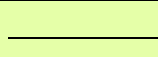 & - kg.ha ${ }^{-1}$ & \\
\hline IAC 12 & $1,68 \mathrm{~cd}$ & $2,20 \mathrm{cde}$ & $1,56 \mathrm{bc}$ & $0,78 b c$ & 0,60de & $0,63 b c$ & $14.977 \mathrm{~b}$ & $23.108 b c$ & $14.358 \mathrm{bc}$ \\
\hline IAC 13 & $2,05 b$ & $2,32 \mathrm{~cd}$ & $1,72 b$ & $0,75 b c$ & $0,79 \mathrm{bc}$ & $0,70 \mathrm{bc}$ & $21.667 a$ & $21.163 b c$ & $12.488 \mathrm{bcd}$ \\
\hline IAC 14 & $2,47 a$ & $3,03 a$ & $2,24 \mathrm{a}$ & $1,39 a$ & $0,97 \mathrm{~b}$ & $0,75 \mathrm{abc}$ & $25.208 a$ & $31.650 \mathrm{a}$ & $21.997 a$ \\
\hline Fécula Branca & 1,49de & 2,05def & $1,53 \mathrm{bcd}$ & $1,17 \mathrm{ab}$ & $1,53 a$ & $0,77 \mathrm{ab}$ & $10.116 \mathrm{bcd}$ & $15.642 c$ & 10.400 cde \\
\hline Espeto & $1,26 \mathrm{ef}$ & $1,94 \mathrm{ef}$ & $1,24 \mathrm{de}$ & $0,80 \mathrm{bc}$ & $0,86 \mathrm{bc}$ & $0,72 b c$ & $7.662 \mathrm{~cd}$ & $14.970 \mathrm{c}$ & $4.445 \mathrm{e}$ \\
\hline Branca-de-Sta Catarina & $1,78 \mathrm{c}$ & $2,70 \mathrm{~b}$ & $1,77 \mathrm{~b}$ & $1,06 \mathrm{abc}$ & $0,75 \mathrm{~cd}$ & $0,82 \mathrm{ab}$ & $12.384 b c$ & $28.280 \mathrm{ab}$ & $13.576 \mathrm{bcd}$ \\
\hline Fibra & $1,27 \mathrm{ef}$ & $1,81 \mathrm{f}$ & $1,12 \mathrm{e}$ & $1,18 \mathrm{ab}$ & $1,67 \mathrm{a}$ & $0,96 a$ & $12.176 \mathrm{bc}$ & $17.397 \mathrm{c}$ & 7.136de \\
\hline Verdinha & $1,17 \mathrm{f}$ & $1,93 \mathrm{ef}$ & $1,25 \mathrm{cde}$ & $0,81 b c$ & $0,85 \mathrm{bc}$ & $0,75 \mathrm{abc}$ & $5.857 \mathrm{~d}$ & $15.278 c$ & $4.775 \mathrm{e}$ \\
\hline Mico & $1,63 \mathrm{~cd}$ & $2,46 b c$ & $1,72 b$ & $0,64 \mathrm{c}$ & $0,53 e$ & $0,55 c$ & $14.398 b$ & 26.581ab & $18.247 \mathrm{ab}$ \\
\hline $\mathrm{F}$ & $74,58^{*}$ & $44,67^{*}$ & $27,69^{*}$ & $5,47^{*}$ & $103,17^{*}$ & $6,73^{*}$ & $25,66^{*}$ & $13,50^{*}$ & $19,68^{*}$ \\
\hline Média geral & 1,64 & 2,27 & 1,57 & 0,95 & 0,95 & 0,74 & 13,830 & 21.563 & 11,931 \\
\hline C.V. $(\%)$ & 5,90 & 5,29 & 8,32 & 22,74 & 8,15 & 12,2 & 17,85 & 15,71 & 22,46 \\
\hline
\end{tabular}

* Significativo em nível de $5 \%$ pelo teste F.

Médias seguidas pelas mesmas letras nas colunas não diferem entre si em nível de 5\% pelo teste de Tukey.

facilidade da prática de colheita, sobretudo nas áreas de exploração mecanizada da cultura.

No que concerne à produção de parte aérea (Quadro 4) nos três anos agrícolas a cultivar IAC 14 destacou-se em relação às demais, embora não tenha diferido estatisticamente, no primeiro ano, da cultivar IAC 13; no segundo ano, das cultivares Branca-deSanta Catarina e Mico e, novamente, da cultivar Mico, no terceiro ano avaliado. As menores produções foram detectadas nas cultivares Verdinha e Espeto. Pode-se visualizar que a cultivar IAC 14 apresentou nos três anos agrícolas valores médios superiores de altura de plantas e de produção de parte aérea, em relação às demais cultivares avaliadas. A relação direta entre produção de parte aérea e altura da planta foi relatada por diversos autores (PAUla, 1976; SILVA, 1977; Souza e FASIABEn, 1986). Em estudo de correlações entre caracteres de mandioca, GonÇALVES-VIDIGAL et al. (1997) verificaram correlação genotípica positiva e significativa entre a produção de parte aérea e altura das plantas. LORENZI et al. $(1988,1990)$ constataram, em avaliação do comportamento de cultivares de mandioca, a influência de fatores ambientais e de componentes genéticos na produção de parte aérea de mandioca. A produção de parte aérea é fator importante na mandiocultura, tanto como material de propagação (principalmente em regiões que apresen- tem clima adverso para conservação de ramas (SouZA e FASIABEN, 1986)) como produção de forragem para a alimentação animal.

Quanto à produção de raízes tuberosas (Quadro 5), no primeiro experimento a cultivar Fécula Branca foi a mais produtiva $\left(29,4\right.$ t.ha $\left.{ }^{-1}\right)$ diferindo estatisticamente apenas das cultivares IAC 13, IAC 12 e Branca-de-Santa Catarina. No segundo experimento de avaliação as maiores produções foram obtidas nas cultivares Verdinha, Fécula Branca, Espeto e Fibra. No terceiro experimento de avaliação novamente a cultivar Fécula Branca destacou-se em produtividade, desta vez superando todas as demais cultivares testadas, com exceção da cultivar Mico. O terceiro ano de avaliação caracterizou-se por ser um período bastante chuvoso, fato que contribuiu para que ocorresse uma incidência muito elevada de bacteriose, em relação aos dois períodos anteriores de avaliação. Em vista disso, as cultivares Espeto, Fibra e Verdinha foram severamente atacadas, o que resultou em redução acentuada da produtividade das mesmas neste último período de avaliação.

Tendo em vista que as colheitas foram realizadas em um ciclo vegetativo (10 meses), é possível inferir que as cultivares mais produtivas sejam mais precoces em relação às demais; entretanto, para que isso seja confirmado, torna-se necessária a condução de 
Quadro 5. Médias e análise de variância das seguintes características: produção de raízes tuberosas (PRODRAIZ), matéria seca (MS) e índice de colheita (IC), obtidas no ensaio regional de cultivares de mandioca em Araruna (PR), durante os anos agrícolas de $1994 / 95,1995 / 96$ e 1996/97

\begin{tabular}{|c|c|c|c|c|c|c|c|c|c|}
\hline \multirow{4}{*}{ Cultivares } & \multicolumn{9}{|c|}{ Características } \\
\hline & \multicolumn{3}{|c|}{ PRODRAIZ } & \multicolumn{3}{|c|}{ MS } & \multicolumn{3}{|c|}{ IC } \\
\hline & $1994 / 95$ & $1995 / 96$ & $1996 / 97$ & $1994 / 95$ & $1995 / 96$ & $1996 / 97$ & $1994 / 95$ & $1995 / 96$ & $1996 / 97$ \\
\hline & \multicolumn{3}{|c|}{ t.ha ${ }^{-1}$} & \multicolumn{3}{|c|}{ g. $\mathrm{kg}^{-1}$} & \multicolumn{3}{|c|}{$\%$} \\
\hline IAC 12 & $20,5 b c d$ & $17,4 \mathrm{c}$ & $21,3 b c$ & 358abcd & $373 a b$ & $339 a b$ & $58 \mathrm{~cd}$ & $43 c$ & $60 \mathrm{~b}$ \\
\hline IAC 13 & $17,1 \mathrm{~cd}$ & $17,3 c$ & $19,1 \mathrm{bcd}$ & $366 a b c$ & $376 a$ & $332 \mathrm{ab}$ & $45 \mathrm{e}$ & $45 c$ & $61 b$ \\
\hline IAC 14 & $25,8 \mathrm{ab}$ & $19,1 \mathrm{bc}$ & $20,1 b c$ & $380 a$ & $363 a b c$ & $354 a$ & $51 \mathrm{de}$ & $38 c$ & $48 c$ \\
\hline Fécula Branca & $29,4 \mathrm{a}$ & $28,1 \mathrm{a}$ & $30,2 \mathrm{a}$ & $372 \mathrm{ab}$ & $378 a$ & $342 \mathrm{ab}$ & $75 \mathrm{ab}$ & $65 \mathrm{ab}$ & $74 a$ \\
\hline Espeto & $26,6 \mathrm{ab}$ & $27,7 a$ & $11,9 d$ & $341 d$ & $323 e$ & $330 \mathrm{ab}$ & $78 \mathrm{a}$ & $65 \mathrm{ab}$ & $73 a$ \\
\hline Branca-de-Sta Catarina & $13,8 \mathrm{~d}$ & $18,3 \mathrm{bc}$ & $12,4 \mathrm{~d}$ & $341 d$ & $363 \mathrm{abc}$ & $313 b$ & 53de & $39 c$ & $48 c$ \\
\hline Fibra & $25,0 \mathrm{abc}$ & $23,4 \mathrm{ab}$ & $18,6 \mathrm{bcd}$ & $354 \mathrm{bcd}$ & $354 b c$ & $334 a b$ & $67 \mathrm{bc}$ & $57 \mathrm{~b}$ & $73 a$ \\
\hline Verdinha & $21,8 \mathrm{abc}$ & $28,2 \mathrm{a}$ & $13,8 \mathrm{~cd}$ & $342 \mathrm{~cd}$ & 329de & $318 b$ & $79 a$ & $65 \mathrm{ab}$ & $74 a$ \\
\hline Mico & $25,9 \mathrm{ab}$ & $21,7 \mathrm{bc}$ & $24,6 \mathrm{ab}$ & $352 \mathrm{bcd}$ & $347 c d$ & $339 a b$ & $64 c$ & $45 c$ & $58 b$ \\
\hline $\mathrm{F}$ & $9,25^{*}$ & $16,42^{*}$ & $14,07^{*}$ & $7,57^{*}$ & $22,95^{*}$ & $3,58^{*}$ & $40,33^{*}$ & $51,89^{*}$ & $54,44^{*}$ \\
\hline Média geral & 22,9 & 22,4 & 19,11 & 356 & 356 & 334 & 63 & 0,51 & 63 \\
\hline C.V. $(\%)$ & 14,44 & 10,31 & 16,64 & 2,91 & 2,35 & 3,95 & 6,21 & 6,19 & 4,68 \\
\hline
\end{tabular}

* Significativo em nível de $5 \%$ pelo teste F.

Médias seguidas pelas mesmas letras nas colunas não diferem entre si em nível de $5 \%$ pelo teste de Tukey.

ensaios de maior duração, uma vez que muitos produtores preferem efetuar colheitas mais tardiamente e/ou em dois ciclos vegetativos.

Com relação aos teores de matéria seca das raízes tuberosas (Quadro 5), observou-se no ano agrícola 1994/95 que a cultivar IAC 14 apresentou os maiores teores de matéria seca , não diferindo, entretanto, das cultivares Fécula Branca, IAC 13 e IAC 12. Por outro lado, as cultivares Fécula Branca e IAC 13 apresentaram os maiores teores no segundo experimento, embora não diferindo significativamente de IAC 12, IAC 14 e Branca-de-Santa Catarina. No terceiro ano agrícola, a cultivar IAC 14 superou as demais, diferindo apenas das cultivares Branca-de-Santa Catarina e Verdinha. As cultivares que apresentaram menores teores de matéria seca foram: Espeto e Branca-deSanta Catarina no primeiro experimento; Espeto e Verdinha no segundo experimento; e as cultivares Verdinha e Branca-de-Santa Catarina no terceiro experimento.

O teor de matéria seca é, normalmente, a característica que determina o maior ou menor valor pago pelas indústrias aos produtores no momento da comercialização, uma vez que está diretamente relacionada ao rendimento industrial dos diversos produtos derivados da mandioca (SARMENTO, 1997). Nesse contexto é desejável que as mesmas cultivares respon- sáveis pelas maiores produções de raízes tuberosas sejam também aquelas que apresentem os maiores teores de matéria seca, maximizando o rendimento do produto final por unidade de área cultivada.

Para a característica índice de colheita (Quadro 5) as cultivares Fécula Branca, Espeto e Verdinha apresentaram os maiores valores nos três experimentos de avaliação de cultivares. No ano agrícola 1996/97 a cultivar Fibra exibiu elevada magnitude de índice de colheita, fato que a tornou similar às cultivares supracitadas. Um aspecto interessante, neste estudo, é a constatação da superioridade de comportamento da cultivar Fécula Branca à qual deve ser dada maior ênfase, por ter apresentado elevado índice de colheita e ter sido a mais produtiva.

\section{CONCLUSÕES}

1. As cultivares Mico, IAC 14 e Fécula Branca apresentaram maior resistência à bacteriose;

2. Nos três anos de avaliação as maiores produções de parte aérea foram obtidas com a cultivar IAC 14, ao passo que as cultivares Fécula Branca, Mico, Fibra, Espeto, IAC 14 e Verdinha apresentaram as maiores produções de raízes tuberosas;

3. As cultivares IAC 14, Fécula Branca, IAC 13 e IAC 12 foram superiores quanto aos teores de matéria seca das raízes; 
4. A cultivar Fécula Branca por apresentar resistência à bacteriose e ser a mais produtiva pode ser recomendada para cultivo na região de Araruna.

\section{AGRADECIMENTO}

À Pinduca Indústria Alimentícia Ltda, de Araruna (PR), pelo financiamento do projeto.

\section{REFERÊNCIAS BIBLIOGRÁFICAS}

ABBUD, N.S. IAPAR-19, uma nova variedade de mandioca-de-mesa, que pode-se fritar sem cozimento prévio. In: CONGRESSO BRASILEIRO DE MANDIOCA, 4. 1986, Balneário Camboriú. Resumos... Balneário Camboriú, SBM, p.84.

BANZATTO, D.A.; KRONKA, S.N. Experimentação agrícola. 3.ed. Jaboticabal: FUNEP, 1995. 247p.

CONCEIÇÃO, A.J. A Mandioca. Cruz das Almas: UFBA/ EMBRAPA/BN/BRASCAN NORDESTE, 1979.382 p.

DORETTO, M. Distribuição da cultura da mandioca no Paraná nos anos 80. Londrina: IAPAR, 1993. 19 p. (Informe de Pesquisa, 102).

FUKUDA, W.M.G. Obtenção e seleção de clones avançados de mandioca. In: CURSO INTENSIVO NACIONAL DE MANDIOCA, 8. Cruz das Almas: CNPMF, 1993. 24p.

FUKUDA, W.M.G. Melhoramento da mandioca. In: BOREM, A. (ed.), MELHORAMENTO DE ESPÉCIES CULTIVADAS. Viçosa: UFV, 1999. p. 409-428.

FUKUDA, W.M.G.; CALDAS, R. C.; FUKUDA, C. Comportamento de cultivares e clones de mandioca resitentes à bacteriose. Revista Brasileira de Mandioca, Cruz das Almas, v.2, n.2, p.23-31, 1983.

FUKUDA, C.; ROMEIRO, R.S.; FUKUDA, W.M.G. Avaliação da resistência de cultivares de mandioca a Xanthomonas campestris pv. manihotis. Revista Brasileira de Mandioca, Cruz das Almas, v.3, n.1, p.7-12, 1984.

GONÇALVES-VIDIGAL, M.C.; VIDIGAL FILHO, P.S.; AMARAL JÚNIOR, A.T.; BRACCINI, A. de L. Análise de parâmetros genéticos e correlações simples e canônicas entre características morfoagronômicas e da qualidade das raízes em cultivares de mandioca adaptadas ao noroeste paranaense. Revista Brasileira de Mandioca, Cruz das Almas, v.16, p.41-48, 1997.

GROSMANN, J.; FREITAS, A.G. de. Determinação do teor de matéria seca pelo método de peso específico em raízes de mandioca. Revista Agronômica, Porto Alegre, p.75-80, 1950.

GROXKO, M. Mandioca. In: ACOMPANHAMENTO DA SITUAÇÃO AGROPECUÁRIA NO PARANÁ. Curitiba: SEAB/DERAL, v.23, p.89-95,1997.

LORENZI, J.O.; DIAS, C.A.C. Cultura da mandioca. Campinas: CATI, 1993. 41p. (Boletim Técnico, 211).

LORENZI, J.O.; MONTEIRO, D.A.; CARVALHO, A.P. de; ASSIS, C.M. de O.A.; DEAK, L.G.L.; IGUE, T. Testes regionais de variedades de mandioca de mesa no Estado de São Paulo. In: CONGRESSO BRASILEIRO DE MANDIOCA, 6., 1990. Resumos... Londrina, SBM: 1990. 72p.

LORENZI, J.O.; PEREIRA, A.S.; MONTEIRO, D.A.; RAMMOS, M.T.B. Características agronômicas e culinárias de clones de mandioca. Bragantia, Campinas, v.47, p.247-253, 1988.

MATOS, P.L.P.; DANTAS, J.L.L.; SOUTO, G.F. Mandioca: Pesquisa, evolução agrícola e desenvolvimento tecnológico. Cruz das Almas: EMBRAPA/CNPMF, 1981. 103p. (Documento, 9).

NORMANHA, E.S.; PEREIRA, A.S. Aspectos agronômicos da cultura da mandioca (Manihot utilissima, Pohl). Bragantia, Campinas, v.10, p.179-202, 1950.

PAULA, J.F. Comportamento de variedades de mandioca (Manihot esculenta Crantz) em Viçosa, Minas Gerais. Viçosa, 31p. 1976. Tese (Mestrado em Fitotecnia) - UFV.

SARMENTO, S.B.S. Caracterização da fécula de mandioca (Manihot esculenta Crantz) no período de colheita de cultivares de uso industrial. São Paulo, 1997. 162p. Tese (Doutorado - Faculdade de Ciências Farmacêuticas) - Universidade de São Paulo.

SILVA, S. de O. e. Capacidade de produção e características de raízes e ramas de 60 variedades de mandioca (Manihot esculenta Crantz). Viçosa, 1977. 47p. Tese (Mestrado em Fitotecnia) - UFV.

SILVA, S. de O. e. Instalação e caracterização botânicoagronômica de coleções de mandioca. Cruz das Almas: EMBRAPA/CNPMF, 1981. 51p. (CNPMF-Documentos, 7).

SOUZA, A.B.; FASIABEN, M.C.R. Competição de cultivares de mandioca conduzida em uma pequena propriedade no município de Rio Azul, Paraná. Revista Brasileira de Mandioca, Cruz das Almas, v.5, p.99-104, 1986. 